|| ISSN(online): 2589-8698 || ISSN(print): 2589-868X || International Journal of Medical and Biomedical Studies

Available Online at www.ijmbs.info

PubMed (National Library of Medicine ID: 101738825)

Index Copernicus Value 2018: 75.71

Volume 3, Issue 4; April: 2019; Page No. 126-133

\title{
BIOCHEMICAL AND PATHOLOGICAL ASSESSMENT OF RICINUS COMMUNIS LEAF EXTRACT ADMINISTRATION ON THE LIVER AND KIDNEY IN MICE
}

\author{
Haile Gebreslassie ${ }^{1}$, Peter Etim Ekanem ${ }^{2}$, Mebrahtom Gebrelibanos $^{3}$, Hafte Assefa ${ }^{2}$, Tefera Belsty ${ }^{4}$, \\ Hayelom Kebede Mekonen ${ }^{2}$ \\ ${ }^{1}$ Department of Biomedical Sciences, College of Health Sciences, Aksum University, Axum, Ethiopia \\ ${ }^{2}$ Department of Anatomy, School of Medicine, College of Health Sciences, Mekelle University, Mekelle, \\ Ethiopia. \\ ${ }^{3}$ Department of Pharmacognosy, School of Pharmacy, College of Health Sciences, Mekelle University, \\ Mekelle, Ethiopia \\ ${ }^{4}$ Department of Anatomy, College of Health Sciences, Haramaya University, Harer, Ethiopia
}

Article Info: Received 23 March 2019; Accepted 15 April. 2019

Cite this article as: Gebreslassie, H., Ekanem, P., Gebrelibanos, M., Assefa, H., Belsty, T., \& Kebede, H. (2019). BIOCHEMICAL AND PATHOLOGICAL ASSESSMENT OF RICINUS COMMUNIS LEAF EXTRACT ADMINISTRATION ON LIVER AND KIDNEY IN MICE. International Journal of Medical and Biomedical Studies, 3(4).

DOI: https://doi.org/10.32553/ijmbs.v3i4.192

Address for Correspondence: Peter Etim Ekanem, School of Medicine, College of Health Sciences, Mekelle University

Funding: This project was funded by Mekelle University.

Conflict of interest: No conflict of interest.

\section{Abstract}

Background: Medicinal plants remain the mainstay for primary healthcare. The present study evaluated the effects of sub-acute administration of Ricinus communis fresh leaves' methanolic extract on the histopathology and biochemistry of the liver and kidney in Swiss albino mice.

Methods: 24 male and female mice were randomly assigned into four equal groups. Group I (control) received $5 \%$ tween 80 orally, while the treated groups; II, III and IV received oral Ricinus communis extract at $250 \mathrm{mg} / \mathrm{kg} /$ day, $500 \mathrm{mg} / \mathrm{kg} /$ day, and $1000 \mathrm{mg} / \mathrm{kg} /$ day for 28 consecutive days, respectively. Tissue processing, staining and biochemical analysis were used to assess the changes induced histopathologically and biochemically on the liver and kidney tissues.

Results: Histopathological alterations in liver and kidney sections were observed both in male and female mice. Serum levels of alanine aminotransferase, alkaline phosphatase and aspartate aminotransferase showed significant increment in both sexes. There were no significant changes in serum creatinine at all doses and in both sexes

Conclusion: Methanolic extracts of Ricinus communis fresh leaves had hepatotoxic and nephrotoxic effects.

Key words: Histopathology; Ricinus communis; liver; kidney; biochemical

\begin{tabular}{ll}
\hline ABBREVIATIONS & Ricinus communis \\
RC & Traditional medicine \\
TM & World Health Organization \\
WHO & Organisation for Economic Co-operation and Development \\
OECD & alanine aminotransferase \\
ALT &
\end{tabular}



ALP
AST
$H \& E$
SEM
ANOVA
alkaline phosphatase
aspartate aminotransferase
hematoxylin and eosin
standard error of mean
one-way analysis of variance

\subsection{INTRODUCTION}

A World Health Organization (WHO) survey indicated that about $70-80 \%$ of the world's population relies on non-conventional medicine, mainly of herbal source, in their primary healthcare [1]. Many people in developing countries, particularly those in rural areas, have more access to traditional than modern medicines. The safety of several commercially available herbs has recently come into question due to reports of adverse effects and potential interactions with prescribed drugs [2]. An example of such adverse effects has been reported in a research conducted by Ajibade et al. [3] on the effects of Moringa oleifera seed extract in rats which indicated that the plant causes portal cellular infiltration, periportal congestion and hydropic degeneration of hepatocytes in the liver as well as cortical congestion and interstitial haemorrhage in the kidney. The real drawback in traditional medicine (TM) arises mostly from lack of precision in dosage and nature of diagnosis in especially chronic and complicated conditions [4]. A report by Khleifat et al. [5] indicated that chronic treatment with $50 \mathrm{mg} / \mathrm{kg}$ of Teucrium polium, induced marked cytoplasmic vacuolation of liver and kidney tubular cells. Another report [6] also revealed that treatment of mice with aqueous root extract of Clerodendrum myricoides at 100 and $400 \mathrm{mg} / \mathrm{kg}$ showed several histopathological changes in sections of both liver and kidney.

The Ricinus communis ( $R C$ ) leaf is used to treat ear disease and wounds in some parts of Tigray region, Ethiopia [7]. Even though it is not scientifically reported, this leaf is also commonly used to induce abortion (by mixing with the leaf extract of Phytolocca dedocandra). It is also used to treat human diseases such as impotence and rabies in some parts of Oromia region [8, 9]. In Ethiopia, no studies have been conducted so far to evaluate the possible toxic effects of the fresh leaves of this plant. The present study is aimed at evaluating any possible toxicity associated with the use of fresh leaf of $R C$ on the histopathology of the liver and kidney and some biochemical parameters in mice.

\subsection{Materials and Methods}

A laboratory based experimental design was employed to investigate the toxic effects of fresh methanolic extracts of $R C$ on the histopathology of the liver and kidney as well as some biochemical parameters. The plant specimen was collected from Endamariam Koraro $(64 \mathrm{~km}$ from Mekelle city), and authenticated by a botanist at Mekelle University. Fresh leaves were cut into pieces, weighed and homogenized using mortar and pestle. The three filtrates were combined, evaporated and dried in an oven at $40^{\circ} \mathrm{C}$ to obtain the dried extract.

A total of 24 healthy, 8 week old adult Swiss albino mice of both sexes were used. The female mice were nulliparous and non-gravid. All the experimental animals were obtained from Mekelle University, Veterinary Medicine College. The animals were kept under standard conditions (at room temperature), with a photoperiod of $12 \mathrm{hrs}$ light / $12 \mathrm{hrs}$ dark cycle) based on the Organisation for Economic Cooperation and Development (OECD) guide line 407 [10]. Conventional rodent laboratory diets were used with free access to water. The study was conducted after ethical clearance was obtained from the ethical review board of Mekelle University, College of Health Sciences.

The mice were randomly assigned into 4 groups (1 control and 3 experimental groups). Group-I served as control and was administered with the vehicle (5\% tween 80 ). Group II, III and IV were administered with $250 \mathrm{mg} / \mathrm{kg}, 500 \mathrm{mg} / \mathrm{kg}$ and $1000 \mathrm{mg} / \mathrm{kg}$ of the extracts of $R C$ fresh leaf respectively for a period of 28 consecutive days through oral gavage. The doses were selected 
based on the OECD guideline 407 [10]. The extracts were given once after the animals were fasted of food for 3 hours with a free access of water. In addition, after administration of the plant extract animals were fasted of food for 1 hour and then provided with food [11].

Body weight of each animal in the experimental and control groups was recorded by using Mettler weighing balance (Mettler Toledo, type PG1003-S, Switzerland) once before the start of dosing, weekly during the treatment period and finally on the day of sacrifice. Blood samples were collected by cardiac puncture from mice in each group after they were anaesthetized with diethyl ether for biochemical studies. The samples were collected in plastic test tubes, centrifuged (XC23, Pentral, France) at $3000 \mathrm{rpm}$ for $15 \mathrm{~min}$, after which the serum samples were aspirated and stored at $-20^{\circ} \mathrm{C}[12]$. The serum samples were analyzed to determine the levels of aspartate aminotransferase (AST), alanine aminotransferase (ALT), alkaline phosphatase (ALP) and creatinine using an automated biochemistry analyzer (C400, Pentral, France).

Animals were further weighed, anesthetized, sacrificed by cervical dislocation, and dissected to bring out the liver and kidneys. The organs were examined closely for any lesions then cut and fixed in test tubes containing $10 \%$ buffered formalin for $24 \mathrm{hrs}$.

Liver and kidney tissues were then processed. Semiautomatic microtome (HS3315, feedo, China) was used for sectioning of tissue blocks at a thickness of $5 \mu \mathrm{m}$. Slides of liver and kidney sections were stained with H\&E. Stained tissue sections were then carefully examined under a compound light microscope. Photomicrographs of selected slides from both the treated and control groups were taken under a magnification of $40 \mathrm{X}$ objective using a digital photo camera fitted microscope (B-380, OPTIKA, and Italy). Tissue sections from the treated groups were examined for any evidence of histopathological changes compared with the control. All the histopathological changes were confirmed by a pathologist.

All data were analyzed by SPSS version 20 statistical software. All values of parameters were expressed in mean \pm SEM (standard error of mean). Treatment over time was compared between control and treated groups by using one-way analysis of variance (ANOVA). Level of significance differences was considered at $\mathrm{p}<0.05$.

\subsection{Results}

Table 1: Effect of methanolic Ricinus Communis leaf extract on the biochemical parameters of female mice in sub-acute toxicity study:

\begin{tabular}{|l|l|l|l|l|}
\hline Biochemical & Control (5\% & \multicolumn{3}{|c|}{ Treatment groups } \\
\cline { 3 - 5 } parameters & Tween 80) & GP II & GP III & GP IV (n*) \\
\hline AST (U/L) & $86.74 \pm 0.53$ & $87.11 \pm 0.52(1.00)$ & $89.28 \pm 0.07(0.52)$ & $125.17 \pm 3.06(0.00)^{*}$ \\
ALT (U/L) & $75.88 \pm 0.33$ & $75.87 \pm 0.35(1.00)$ & $78.31 \pm 0.17(0.08)$ & $108.52 \pm 0.31(0.00)^{*}$ \\
ALP (U/L) & $56.81 \pm 0.56$ & $57.42 \pm 0.28(0.98)$ & $59.07 \pm 0.10(0.06)$ & $79.39 \pm 0.02(0.00)^{*}$ \\
Creatinine(mg/dl) & $0.65 \pm 0.45$ & $0.86 \pm 0.33(0.99)$ & $1.23 \pm 0.03(0.81)$ & $0.70 \pm 0.40(1.00)$ \\
\hline
\end{tabular}


Values are expressed as Mean \pm SEM. The figures in brackets indicate the calculated $p$ values of the treatment groups as compared with the control. The figures with star $\left({ }^{*}\right)$ indicate a statistically significance difference. $(P<0.05)$

Table 2: Effects of methanolic Ricinus communis leaf extract on the biochemical parameters of male mice in sub-acute toxicity study:

\begin{tabular}{|l|l|l|l|l|}
\hline Biochemical & Control (5\% & \multicolumn{3}{|c|}{ Treatment groups } \\
\cline { 3 - 5 } parameters & Tween 80) & GP II & GP III & GP IV (n*) \\
\hline AST (U/L) & $86.65 \pm 0.71$ & $88.75 \pm 0.78(0.72)$ & $88.76 \pm 0.72(0.72)$ & $123.45 \pm 2.18(0.00)^{*}$ \\
ALT (U/L) & $75.60 \pm 0.74$ & $77.80 \pm 0.73(0.14)$ & $76.78 \pm 0.77(0.76)$ & $109.17 \pm 0.05(0.00)^{*}$ \\
ALP (U/L) & $57.16 \pm 0.60$ & $58.71 \pm 0.81(0.41)$ & $57.55 \pm 0.55(0.99)$ & $79.61 \pm 0.28(0.00)^{*}$ \\
Creatinine(mg/dl) & $0.30 \pm 0.10$ & $0.53 \pm 0.23(0.99)$ & $1.00 \pm 0.20(0.53)$ & $0.85 \pm 0.45(0.85)$ \\
\hline
\end{tabular}

Values are expressed as Mean \pm SEM. The figures in brackets indicate the calculated $p$ values of the treatment groups as compared with the control. The figures with star $\left(^{*}\right)$ indicate a statistically significance difference. $(P<0.05)$

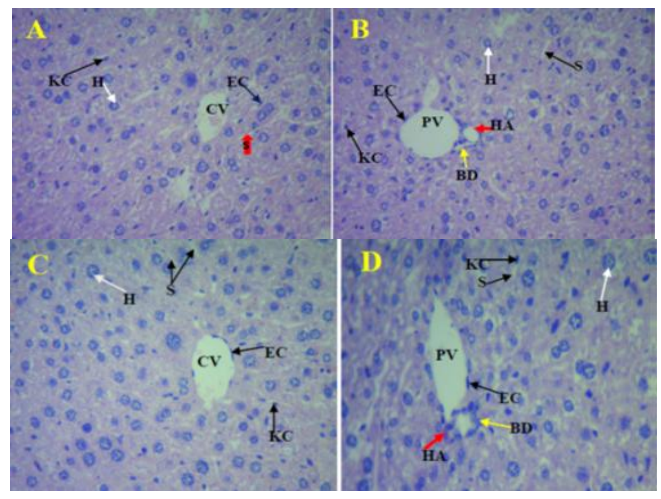

Figure 1: Photomicrographs of liver sections from female (A \& B) and male (C \& D) control mice; showing normal features that would be used for comparison with the treated groups. Central Vein (CV), Portal Vein (PV), Bile Duct (BD) and Hepatic Artery (HA), radiating Hepatocytes (H), hepatic Sinusoids (S), kupffer Cells (KC) and endothelial cells (EC). (H\&E; 400X) 


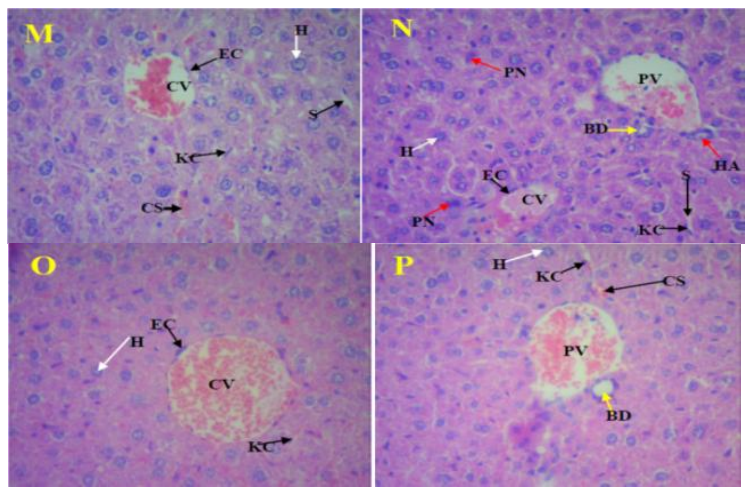

Figure 2: Photomicrographs of liver sections from female ( $\mathbf{M} \& \mathbf{N})$ and male $(\mathbf{O} \& \mathbf{P})$ mice treated with $1000 \mathrm{mg} / \mathrm{kg} /$ day of the extract; showing moderate dilation and congestion of portal veins (PV), moderate congestion of central vein (CV), slight congestion of sinusoids (CS), and pyknotic nuclei (PN) were observed in both female and male mice as compared to the control group.); Hepatocytes $(\mathbf{H})$,, Kupffer cells (KC), Endothelial cells Portal, Hepatic artery (HA), Bile duct (BD); H\& E; 400X

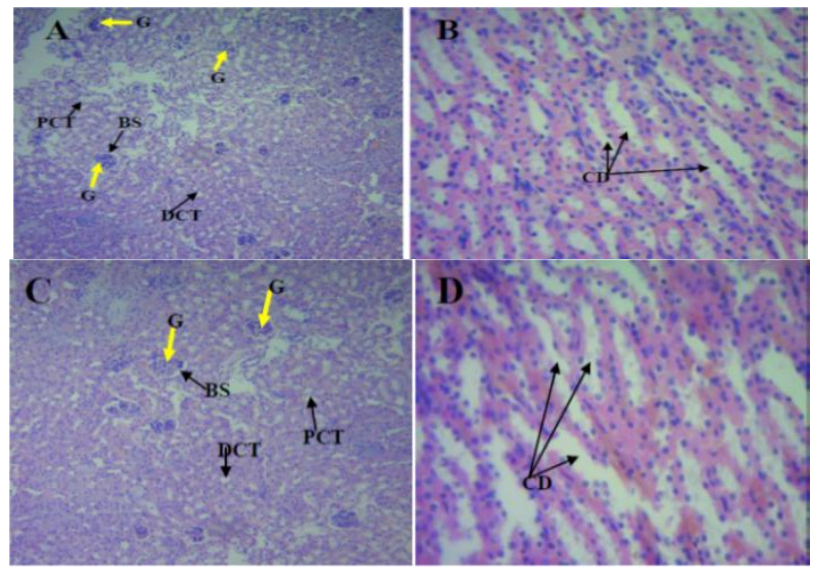

Figure 3: Photomicrographs of sections of kidney from female (A \& B) and male (C \& D) control mice; showing normal appearance of the glomerulus (G), bowman's space (BS), proximal and distal convoluted tubules (PCT and DCT respectively) and collecting ducts (CD) H\&E, 400X.

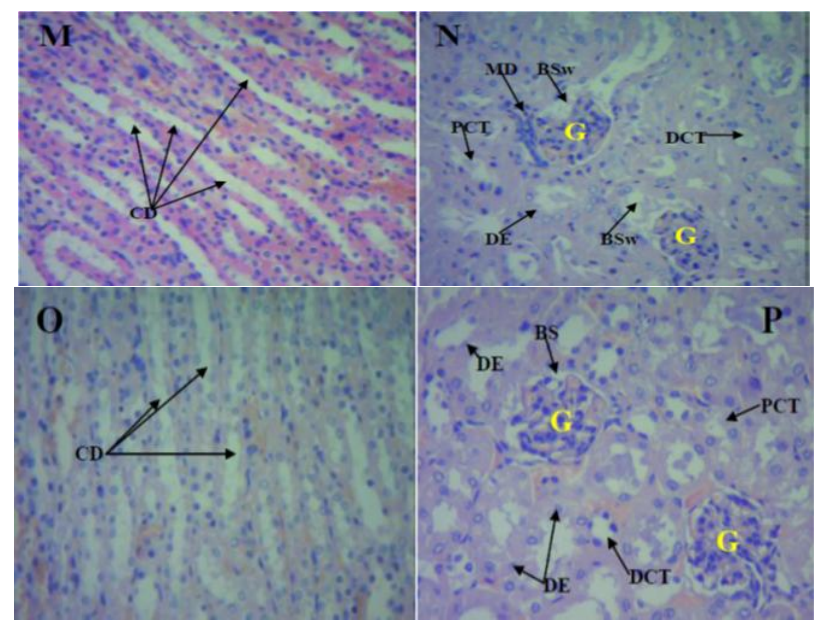

Figure 4: Photomicrographs of sections of kidney from female ( $\mathbf{M} \& \mathbf{N})$ and male $(\mathbf{O} \& \mathbf{P})$ mice treated with $1000 \mathrm{mg} / \mathrm{kg} /$ day of the extract; showing the collecting ducts (CD), degeneration of epithelial cells lining renal tubules (DE) and widening of bowman's space (BSw). Note: Glomerulus (G), Proximal 
convoluted tubule (PCT), Distal convoluted tubule (DCT), Bowman's space (BS), Collecting Ducts (CD), Blood vessel (BV), Macula densa (MD),. (H\&E; 400X)

\subsection{Discussion}

In the present study, mice treated with $250 \mathrm{mg} / \mathrm{kg}, 500 \mathrm{mg} / \mathrm{kg}$ and $1000 \mathrm{mg} / \mathrm{kg}$ per day of the extract were observed to have multiple behavioral changes such as: depression, reduced locomotion, fatigue, head drooping, sleepiness, fur erection and fast breathing. In support of our study, Muhammad et al. [13] revealed that behavioral changes such as depression, sluggishness, and mild diarrhea (in their acute toxicity study) as well as decreased appetite, increased water consumption and frequent urination (in their sub-chronic toxicity study) were observed, especially in those rats given the highest dose of the seed suspension of Ricinus communis. In contrast, Sadashiv [14] reported that mice treated with different dose levels of $R C$ leaf extract showed no significant changes in behavior before and after the administration. The observed reduction in the activity and behavioral changes of the mice at all doses of the extract in this work may be due to the reduction of food intake by the mice over time which probably affected the function of many organsystems including the central nervous system.

The serum levels of AST, ALT and ALP showed a statistically significant increase in both female and male mice treated with the high dose (1000 $\mathrm{mg} / \mathrm{kg} /$ day) of the extract (Tables 1\&2). Another study [13] also corroborated our findings with similar significant increment observed in the serum levels of AST, ALT and ALP in rats treated with high doses of $R C$ seed suspension in their work. However, this is disproved by another report which showed significant decrease in serum levels of AST and ALP and significant increase in the levels of ALT in mice treated with the ethanolic leaves extract of $R C$ for two weeks (acute toxicity study) [15]. These liver enzymes; AST, ALT, and ALP are important in the diagnosis of liver function and are considered as markers of liver dysfunction. The levels of these enzymes become high during drug intoxication [16]. This remarkable elevation in serum levels of the liver biomarkers (AST, ALT and ALP) in this study could, therefore, be symptomatic of hepatocellular damage and histological changes induced by the extract. Validation of our findings has been supported by Kpomah et al. [17] who reported that a dose dependent significant increase in AST, ALT and ALP could indicate disruption in the integrity of the plasma membrane of hepatocytes and loss of cellular components into the blood; which are indications of liver inflammation or damage. Conversely, serum levels of creatinine did not significantly change in mice treated with the extract at all doses compared with the control group. This finding is not supported by the postulation of Salman et al. [15]; who delineated that serum levels of creatinine were significantly decreased in mice treated with $R C$ leaf extract for two weeks (acute toxicity study). The disparity of reports might be due to differences in research design and the environmental factors relating to the concentration of the phytochemical components.

Histopathological alterations were observed in the liver and kidney of both female and male mice. These changes include: slight dilation in central veins and congestion in the portal veins, slight congestion of sinusoids, congestion of central and portal veins, cytoplasmic vacuolation of hepatocytes, activation of kupffer cells and pyknotic nuclei (Figures 182). These changes were observed in treated mice with increasing severity in higher doses. Another RC study revealed that histopathological changes caused by the extract were hemorrhage, congestion, and mild atrophy of various cellular components of the visceral organs (lung, liver, spleen, kidney, heart and testes) [18]. Ebeye et al. [19] reported that saponins are known to be toxic to the body system and could cause vascular congestion. Several authors have submitted from their works that phytochemicals contain free radical scavenging molecules which can cause extensive biological damage to the tissues [20]. The 
changes in the histological sections of the liver may be due to the effect of these secondary metabolites, such as: recinine, saponins, alkaloids, flavonoids, glycosides and steroids found in the RC. Cytoplasmic vacuolation of hepatocytes may be due to the development and accumulation of ions and water in the cytosol which percolates through leaky membranes of organelles [21]. In support of this assertion, another study showed cytoplasmic vacuolation of hepatocytes which occurs when the cytoplasm becomes pale and swollen due to accumulation of fluid or lipids leading to disruption in lipid inclusions and fat metabolism [22]. This process may also activate Kupffer cell proliferation in the liver tissue as seen in the histopathology.

The kidneys are routinely exposed to high concentrations of medications or their metabolites because of their intrinsic functions which include: metabolizing, concentrating, and excreting compounds. Shrinkage of the glomerulus, widening of the bowman space and mild congestion of blood vessels were observed in kidney sections of mice treated with the extract at doses of 500 and $1000 \mathrm{mg} / \mathrm{kg} /$ day (Figures 3\&4). The glomerular shrinkage may be due to the slowing of glomerular vascular circulation or tissue hypoxia which may result in impaired outflow of venous blood from the tissue. The dilation of the Bowman space at higher doses of the extract could also be linked to increased body fluids and metabolites [21].

\subsection{Conclusion}

The results suggest that the methanolic extract of $R C$ fresh leaves may have hepatotoxic and nephrotoxic effects at high doses.

\subsection{Acknowledgements}

The authors would like to acknowledge Mekelle University and the members of Human Anatomy Department for their assistance and cooperation. We also thank Dr. Kendi Nyaga for her contribution in editing and typesetting.

\section{References}

1. World Helath Organization. General guidelines for methodologies on research and evaluation of traditional Medicine Annexure II. Research guidelines for evaluating the safety and efficacy of herbal Medicines. Switzerland, Geneva; 2000:25-29.

2. Popatal A, Sherara $\mathrm{HN}$ and Malkiewieta (). The toxicity of Calliepis Laureola, a South african traditional herbal medicine. J Clin Biochem Nutr 2001;34(2):229-236.

3. Ajibade, TO, Olayemi, FO and Arowolo RO.The haematological and biochemical effects of methanol extract of the seeds of Moringa oleifera in rats. J Med Plants Res. 2012;6(4):617-619

4. Abebe D. and Ayehu A. Medicinal Plants and Enigmatic Health Practice of North Ethiopia. Addis Ababa: Berehanina-Selam Printing Enterprise; 1993:495-496.

5. Khleifat K, Shakhanabeh J and Tarawneh K. The chronic effect of Teucrium polium on some blood parameters and histopathology of liver and kidney in the rat. TURK J BIOL. 2002;26:65-71.

6. Hayelom $K$, Mekbeb $A$, Eyasu $M$, Wondwossen E, Kelbesa U. Methanolic effect of Clerodendrum myricoides root extract on blood, liver and kidney tissues of mice. Afri. Health SCi. 2012;12(4): 489-497.

7. Gebremedhin, A. Local use of spices, condiments and non-edible oil crops in some selected woredas in Tigray, Northern Ethiopia; 2008:50-52;

8. Megersa M, Asfaw Z, Kelbesa E, Beyene A and Woldeabe B. An ethnobotanical study of medicinal plants in Wayu Tuka District, East Welega Zone of Oromia Regional State, West Ethiopia. J Ethnobiol Ethnomed. 2013;9 (68):7.

9. Bekele $G$ and Reddy RP. Ethnobotanical Study of Medicinal Plants Used to Treat Human Ailments by Guji Oromo Tribes in Abaya District, Borana, Oromia, Ethiopia. Univers J Plant Sci. 2015;3(1):4.

10. Organisation for Economic Co-operation and Development, Guidelines for the testing of 
chemicals no. 407. Repeated dose 28-day oral toxicity study in rodents; 2008:1-13.

11. Debelo N, Afework M, Debella A, Geleta B, Makonnen E. Assessment of Hematological, Biochemical and Histopathological Effects of Acute and Sub-chronic Administration of the Aqueous Leaves Extract of Thymus schimperi in Rats. JCT 2016;6(2):2-3.

12. Arsad, SS, Esa MN, Hamzah $\mathrm{H}$ and Othman F. Evaluation of acute, sub-acute and sub chronic oral toxicity of Rhaphidophora decursiva (Roxb.) Schott extract in male Sprague Dawley rats. I Med Plants Res. 2013;7(41):3032.

13. Muhammad BY, Alhassan AJ and Jaafaru IJ (). Toxicity Study of Ricinus cummunis Lnn Seed Suspension in Female Wister Albino Rats. Int J Biochem Res Rev. 2015;7(3):139-147.

14. Sadashiv PS. Acute toxicity study for Ricinus communis. Der Pharm Lett. 2011;3(5):132137.

15. Salman $\mathrm{SI}$, Habeeb MH, Hassan Al, Jasaa AL, Saleh SG and Helal HZ. Effect of ethanolic extract of $R C L$. on some Biochemical parameters and hormones in male mice. Res. J. Pharm., Biol. Chem. Sci.. 2017;8(2):17.

16. Thaba BR and Walia A. Liver function tests and their interpretation. IJP. 2007;74:663671.
17. Kpomah, E.D., Arhoghro, E.M., Uwakwe, A.A. (2012). Biochemical and histopathological changes in Wistar rats following chronic administration of Diherbal mixture of Zanthoxylum leprieurii and Piper guineense. J. of Nat. Sci. Res; 2(6): pp 22

18. Kumar OM, Sugendran K, Pant SC, and Vijayaragha R.. Effect of Ricin on Some Biochemical, Haematological, and Histopathological Variables in Mice. Def Sci J; 2004;54(4):496.

19. Ebeye, OA, Ekundina OV and Wilkie IE. Histological and biochemical effects of aqueous extract of ocimum gratissimum on the liver and kidney of adult wistar rats. Afr. J. Cell. Path. 2014;2:59-64

20. Rodriguez- Meizoso I, Jaime L, Santoyo $S$, Cifuentes A, Garcia-Blairsy RG, Senorans FJ, Ibanez E. Pressurized fluid extraction of bioactive compounds from Phormidium species. J Agric Food Chem. 2008;56(10): 3517-23.

21. Sarhan OM and Al-Sahhaf ZY. Histological and Biochemical Effects of Diazinon on Liver and Kidney of Rabbits. Life Sci.. 2011;8 (4): 1187.

22. Ebaid, H, Dkhil, M, Danfour M, Tohamy A \& Gabry M. Piroxicam-induced Hepatic and Renal Histopathological Changes in Mice. Libyan J Med.2007;2:1-13 